\title{
Diversidade e diferença: movimentos do currículo nos murais de uma escola
}

\author{
Diversity and difference: \\ movements of the curriculum in the murals of a school
}

Diversidad y diferencia: movimientos del currículo en los murales de una escuela

\author{
Amarildo Inácio dos Santos ${ }^{2}$ \\ Gicele Maria Cervi ${ }^{3}$
}

\begin{abstract}
Resumo: A diversidade atravessa documentos oficiais da educação e ressoa em currículos e práticas pedagógicas produzindo discursos de respeito e tolerância. Este trabalho é de abordagem qualitativa e utiliza como estratégia metodológica a arqueologia de Foucault para analisar condições de possibilidade de irrupção de discursos sobre diversidade na educação brasileira. Foram analisados trabalhos de estudantes expostos em murais de uma escola nos quais três discursos foram mapeados: discurso jurídico, de igualdade e de tolerância. O objetivo é problematizar esses discursos a partir de uma análise ancorada na diferença pensada por Deleuze (1988). Conclui-se que, ao difundir discursos sobre diversidade, o currículo reclama um lugar para as identidades diversas, mas não questiona a norma que as produz. Neste sentido, a diferença deleuzeana permite pensar um currículo que foge da representação, pois a diferença não é, ela varia infinitamente à medida que se repete.
\end{abstract}

Palavras-chave: Currículo. Diferença. Diversidade.

\begin{abstract}
Diversity crosses official education documents and resonates in curricula and pedagogical practices producing discourses of respect and tolerance. This work is a qualitative approach and uses Foucault 's archeology as a methodological strategy to analyze conditions for the emergence of discourses about diversity in Brazilian education. were analyzed works of students exposed in murals of a school in which three discourses were mapped: legal discourse, equality and tolerance. The objective is to problematize these discourses from an analysis anchored in the difference thought by Deleuze (1988). It is concluded that, in spreading discourses on diversity, the curriculum demands a place for diverse identities, but does not question the norm that produces them. In this sense, the deleuzeana difference allows to think a curriculum that escapes of the representation, because the difference is not, it varies infinitely as it repeats itself.
\end{abstract}

Keywords: Curriculum. Difference. Diversity.

Resumen: La diversidad atraviesa documentos oficiales de la educación y resuena en currículos y prácticas pedagógicas produciendo discursos de respeto y tolerancia. Este trabajo es de abordaje cualitativo y utiliza como estrategia metodológica la arqueología de Foucault para analizar condiciones de posibilidad de irrupción de discursos sobre diversidad en la educación brasileña. Se analizaron trabajos de estudiantes expuestos en murales de una escuela en los cuales tres discursos fueron mapeados: discurso jurídico, de igualdad y de tolerancia. El objetivo es problematizar esos discursos a partir de un análisis anclado en la diferencia pensada por Deleuze (1988). Se concluye que, al difundir discursos sobre diversidad, el currículo reclama un lugar para las identidades diversas, pero no cuestiona la norma que las produce. En este sentido, la diferencia deleuzeana permite pensar un currículo que huye de la representación, pues la diferencia no es, ella varía infinitamente a medida que se repite.

Palabras clave: Curriculo. Diferencia. Diversidad.

\footnotetext{
${ }^{1}$ Submetido em: 22 maio 2018 - Aceito em: 20 nov. 2018 - Publicado em: 16 fev. 2019.

${ }^{2}$ Universidade Regional de Blumenau (FURB) - E-mail: amarildoinacio.ds@gmail.com

${ }^{3}$ Universidade Regional de Blumenau (FURB) - E-mail: gicele.cervi@gmail.com
} 


\section{Introdução}

Com o fim da ditadura militar, em 1985, o Brasil entrou em um período de abertura democrática e com base em princípios democráticos foi promulgada a nova Constituição Federal no ano de 1988. O documento atendeu antigas demandas de movimentos sociais em várias frentes produzindo efeitos na esfera jurídica como a judicialização dos preconceitos. A tipificação de condutas como o racismo e a discriminação passou a amparar legalmente diversas leis que foram promulgadas, inclusive no campo da educação. Os princípios democráticos, abarcados pela carta magna passaram a orientar a elaboração de documentos oficiais da educação como a Lei de Diretrizes e Bases da Educação Nacional (LDB 9.394/1996). Alguns desses princípios como a inclusão, a participação e a autonomia passaram a figurar em documentos oficiais que regem e/ou orientam a educação no país. Esses documentos são utilizados como base para construir currículos e projetos políticos pedagógicos fazendo reverberar nas práticas pedagógicas discursos sobre diversidade.

Partindo da noção de diferença, desenvolvida por Deleuze (1988), este trabalho interroga o currículo com o objetivo de problematizar os discursos sobre diversidade mapeados em murais de uma escola pública da Rede Estadual de Ensino de Santa Catarina. Para tanto, a abordagem utilizada é qualitativa e a estratégia metodológica empregada foi a arqueologia de Michel Foucault (2008), pois esta ferramenta metodológica permite identificar as condições históricas que possibilitaram a irrupção dos discursos sobre diversidade na educação brasileira. Para registrar práticas discursivas sobre diversidade, encontradas em trabalhos escolares expostos nos murais da escola, utilizou-se a fotografia. Os registros fotográficos são utilizados para compor as análises feitas a partir da perspectiva da diferença de Gilles Deleuze (1988).

Este trabalho organiza-se da seguinte forma: na seção intitulada "Diversidade e diferença", apresenta-se uma discussão conceitual acerca desses conceitos explicitando as distinções entre eles. Na seção seguinte, contextualiza-se as condições históricas presentes no Brasil que permitiram a irrupção de discursos sobre diversidade na educação por meio da análise de documentos legais como a Constituição Federal do Brasil e documentos oficiais da educação. A seguir, a noção de diversidade é problematizada a partir de um referencial teórico que desvela as relações de poder que a produzem. Posteriormente, os discursos mapeados em trabalhos escolares expostos em murais da instituição pesquisada são problematizados a partir da perspectiva da diferença deleuzeana a fim de responder ao objetivo traçado. Por fim, são apresentadas algumas considerações.

\section{Diversidade e diferença}

A diferença pensada por Deleuze (1988) nada tem a ver com a representação que encontramos na ideia de diversidade. A representação tem a ver com a identidade, isto é, tem relação com aquilo que é idêntico, mas "A diferença não tem nada a ver com o diferente. A redução da diferença ao diferente equivale a uma redução da diferença à identidade" (SILVA, 
2002, p. 66). A diferença a partir de Deleuze (1988) não é a diferença com referente. Não é a diferença entre identidades, mas o que difere da identidade, a diferença em si. A diferença deleuzeana é virtualidade, multiplicidade e a partir dela podemos pensar em linhas de fuga, em possibilidades de resistências às representações significantes.

$\mathrm{Na}$ perspectiva da filosofia da diferença não cabe falar em diversidade, mas em multiplicidade e "multiplicidade não tem nem sujeito nem objeto, mas somente determinações, grandezas, dimensões que não podem crescer sem que mude de natureza" (DELEUZE; GUATTARI, 2011, p. 23). A diferença, ao contrário da diversidade, é devir, está sempre em movimento. "O movimento, por sua vez, implica uma pluralidade de centros, uma superposição de perspectivas, uma imbricação de pontos de vista, uma coexistência de momentos que deformam essencialmente a representação" (DELEUZE, 1988, p. 62-63). Se há uma pluralidade de centros não há, como na ideia de diversidade, uma identidade normativa central a partir da qual as anomias são produzidas. A diferença em si não pode ser capturada pela representação identitária, pois ela a deforma, escapa, devém, varia a cada repetição. "A repetição no eterno retorno aparece sob todos estes aspectos como a potência própria da diferença; e o deslocamento e o disfarce do que se repete só fazem reproduzir a divergência e o descentramento do diferente num só movimento, que é a diaphora como transporte" (DELEUZE, 1988, p. 281). Se a diferença é capturada pelos sistemas de representação ela torna-se identidade, a multiplicidade torna-se diversidade e perde sua potência, pois a diversidade é da ordem da identidade, isto é, da igualdade, já a diferença é variação, devir. "A identidade é. A diferença devém” (SILVA, 2002, p. 66).

Não se trata de recusar os estatutos identitários, mas de questioná-los. Afinal, sabe-se que a identidade é necessária em algumas frentes. Stuart Hall (2012) em seu artigo "Quem precisa da identidade?" nos provoca a pensar sobre isso. O próprio autor responde à questão que levantou. Para Hall (2012) os movimentos sociais precisam da identidade em suas lutas, pois é assumindo identidades que se conquistam direitos socialmente negados a determinados grupos. Assim, cumpre ressaltar que o que se quer com este trabalho não é negar a identidade ou defender seu fim, mas argumentar que ela é produção social do poder e, como tal, produz sujeitos e efeitos sobre seus corpos à medida que os significa. Trata-se de problematizar, desestabilizar, usar o discurso de diversidade para opor-se a ele a partir da perspectiva da filosofia da diferença.

\section{Acerca da estratégia metodológica}

Este trabalho apresenta abordagem qualitativa e na "pesquisa qualitativa a preocupação do pesquisador não é com a representatividade numérica do grupo pesquisado, mas com o aprofundamento da compreensão de um grupo social, de uma organização, de uma instituição, de uma trajetória etc" (GOLDENBERG, 2004, p. 14). O que se quer compreender é como os discursos sobre diversidade chegaram ao campo da educação brasileira atravessando documentos legais e reverberando em práticas pedagógicas na escola. Para isso, utiliza-se como estratégia metodológica a arqueologia de Michel Foucault (2008). O filósofo pretende, com sua ferramenta arqueológica, verificar as condições de possibilidade 
de surgimento de discursos que circulam e produzem saberes que instauram regimes de verdade sobre os objetos de que falam. "A arqueologia é uma história das condições históricas de possibilidade do saber" (CASTRO, 2016, p. 40). Para Foucault (2008), o discurso produz os objetos de que fala. O discurso sobre a loucura difundido pela psicopatologia no século XIX, por exemplo, produziu seu objeto, a loucura. Uma vez produzida a loucura, diferentes instâncias de saber, como a medicina, o direito, a psiquiatria, etc., produziram diversos discursos que colocaram em circulação regimes de verdade sobre ela. Discursos médicos, jurídicos, psiquiátricos, etc., produziram os sujeitos da loucura, os loucos. O sujeito, portanto, é um efeito discursivo.

Foucault (2008) delimita recortes históricos como objeto de análise a fim de identificar as condições sociais presentes no período analisado que possibilitaram que determinados discursos funcionassem como verdadeiros e outros não. Para Foucault (2008), a história não é uma sucessão evolutiva de fatos, mas uma sucessão de rupturas, de descontinuidades discursivas. "Foucault define discurso como o "conjunto de enunciados que provém de um mesmo sistema de formação; assim se poderia falar de discurso clínico, discurso econômico, discurso da história natural, discurso psiquiátrico"” (CASTRO, 2016, p. 117). No que concerne a este trabalho interessa analisar algumas condições sociais que emergiram no Brasil, especialmente após 1980, que permitiram a irrupção de discursos sobre a diversidade no campo da educação brasileira, bem como, mapear práticas discursivas sobre diversidade em uma escola pública.

As práticas discursivas sobre diversidade foram mapeadas em trabalhos escolares de estudantes expostos nos murais da escola e registradas fotograficamente, pois tomamos "[...] as imagens como um texto discursivo e enunciativo, visível, que também conta a nossa história contemporânea" (SCHWENGBER, 2014, p. 267). As fotografias são utilizadas para problematizar, a partir da perspectiva da diferença pensada por Gilles Deleuze (1988), a noção de diversidade que sustenta práticas discursivas na escola pesquisada.

\section{Condições de possibilidade de discursos sobre diversidade na escola brasileira}

As lutas de movimentos feministas que crescem no Brasil a partir de 1960, os movimentos LGBT, movimentos dos negros, movimentos estudantis, movimentos que reivindicam a inclusão de pessoas com deficiências, etc., obtiveram grandes conquistas com o início do período de abertura democrática no Brasil, sobretudo, após 1988. Muitas de suas demandas foram contempladas pela nova Constituição Federal construída a partir de princípios democráticos. O novo documento instaurou, por exemplo, a judicialização dos preconceitos prevendo em seu artigo $5^{\circ}$ o princípio da isonomia. "Art. $5^{\circ}$ Todos são iguais perante a lei, sem distinção de qualquer natureza [...]” (BRASIL, 1988). O artigo $3^{\circ}$ do referido texto legal apresenta os objetivos fundamentais da República Federativa do Brasil e em seu inciso IV determina: "IV - promover o bem de todos, sem preconceitos de origem, raça, sexo, cor, idade e quaisquer outras formas de discriminação" (BRASIL, 1988). No que se refere à gênero, em 1990 a Organização Mundial da Saúde (OMS) deixou de considerar a 
homossexualidade uma patologia mental.

O princípio de isonomia, a judicialização dos preconceitos e a despatologização da homossexualidade foram algumas das condições históricas que possibilitaram a irrupção de discursos sobre a diversidade que começou a conquistar espaço na grande mídia invadindo programas de entretenimento, novelas, programas de auditório e provocando discussões polêmicas nas redes sociais. As artes, de um modo geral, contribuíram (e contribuem) para provocar, propor reflexões e questionar as prescrições normativas reclamando o lugar dos diversos. Os discursos sobre diversidade engrossaram o coro ao longo das décadas seguintes e materializaram leis garantindo direitos àqueles considerados diversos. Um exemplo é a Lei $\mathrm{n}^{\mathrm{o}} 7.716$ de 1989 que define os crimes resultantes de preconceito de raça ou de cor.

A entrada em vigência de uma lei produz imediatamente efeitos na esfera jurídica e instaura toda uma trama discursiva que se produz a partir dos saberes relativos ao campo jurídico. No caso das leis demandadas por movimentos sociais e promulgadas, sua vigência passou a produzir um silenciamento dos racismos. A judicialização dos preconceitos produziu o silenciamento por receio das punições legais previstas. "É preciso que, à ideia de cada crime [...] esteja associada a ideia de um determinado castigo, com as desvantagens precisas que dele resultam" (FOUCAULT, 2007, p. 80). A partir do momento em que há uma judicialização dos preconceitos, os discursos sobre os diversos começam a mudar e isso repercute na sociedade tornando a existência daqueles que destoam da norma menos abjeta.

O abjeto designa aqui precisamente aquelas zonas "inóspitas" e "inabitáveis" da vida social, que são, não obstante, densamente povoadas por aqueles que não gozam do status de sujeito, mas cujo habitar sob o signo do "inabitável” é necessário para que o domínio do sujeito seja circunscrito (BUTLER, 1999, p. 155).

As identidades abjetas passam a ser assumidas para obter direitos agora previstos em leis vigentes. A constituição é a carta magna, a lei maior, em função disso deve ressoar em todos os textos legais produzidos no país a partir de sua vigência. Deste modo, a judicialização dos preconceitos reverberou em documentos oficiais sobre a educação produzindo efeitos nas escolas que passaram a ter novos princípios como a inclusão, a participação e a autonomia.

Na LDB de 1996, por exemplo, o termo diversidade aparece duas vezes. No inciso XII do artigo $3^{\circ}$ alude ao respeito à diversidade étnico-racial nos processos educativos. No artigo 33 refere-se ao respeito à diversidade cultural religiosa do Brasil sendo vedadas quaisquer formas de proselitismo (BRASIL, 1996).

No documento "Parâmetros curriculares nacionais: terceiro e quarto ciclos do ensino fundamental: introdução aos parâmetros curriculares nacionais”, de 1998, o termo diversidade aparece 36 vezes e reforça a importância de as escolas reconhecerem, acolherem e respeitarem a diversidade.

A falta de acolhimento é originada muitas vezes pelo fato da escola não reconhecer a diversidade da população a ser atendida, com a consequente diferenciação na demanda. O não reconhecimento da diversidade faz com que toda e qualquer situação que não esteja dentro de um padrão previsto seja tratada como problema do aluno e não como desafio para a equipe escolar. Reconhecer a diversidade e buscar 
formas de acolhimento requer, por parte da equipe escolar, disponibilidade, informações, discussões, reflexões e algumas vezes ajudas externas (BRASIL, 1998, p. 42, grifos dos autores).

No documento "Diretrizes Curriculares Nacionais para Educação Básica” de 2013, o termo diversidade aparece 252 vezes e a importância de considerar a diversidade nos processos educacionais é novamente reforçada.

Torna-se inadiável trazer para o debate os princípios e as práticas de um processo de inclusão social, que garanta o acesso e considere a diversidade humana, social, cultural, econômica dos grupos historicamente excluídos. Trata-se das questões de classe, gênero, raça, etnia, geração, constituídas por categorias que se entrelaçam na vida social - pobres, mulheres, afrodescendentes, indígenas, pessoas com deficiência, as populações do campo, os de diferentes orientações sexuais, os sujeitos albergados, aqueles em situação de rua, em privação de liberdade - todos que compõem a diversidade que é a sociedade brasileira e que começam a ser contemplados pelas políticas públicas (BRASIL, 2013, p. 16, grifos dos autores).

Na nova Base Nacional Comum Curricular (BNCC), cuja versão final foi entregue em 2017, o termo diversidade aparece 147 vezes figurando, inclusive, entre as competências gerais da BNCC que assinala a importância de compreender-se como sujeito na diversidade humana e saber lidar com ela. "Conhecer-se, apreciar-se e cuidar de sua saúde física e emocional, compreendendo-se na diversidade humana e reconhecendo suas emoções e as dos outros, com autocrítica e capacidade para lidar com elas" (BRASIL, 2017, p. 10).

\section{Problematizações acerca do discurso de diversidade}

O discurso de diversidade se apoia sobre os pilares da representação, mas "A representação tem apenas um centro, uma perspectiva única e fugidia e, portanto, uma falsa profundidade; ela mediatiza tudo, mas não mobiliza nem move nada" (DELEUZE, 1988, p. 64). A diversidade é composta pelas diversas identidades que orbitam em torno de um núcleo normativo e "A posição central é considerada a posição não problemática" (LOURO, 2012, p. 44). Essas identidades diversas são produto do núcleo normativo, efeitos dele. Assim, pode-se pensar a diversidade como uma produção do poder, como uma captura da potência da multiplicidade. "A noção de unidade aparece unicamente quando se produz numa multiplicidade uma tomada de poder pelo significante ou um processo correspondente de subjetivação" (DELEUZE; GUATTARI, 2011, p. 24). Essa tomada de poder produz o referente a partir do qual as identidades diversas são discursivamente produzidas.

Este trabalho se refere à diversidade no sentido amplo, mas tomemos a título de exemplo as questões de gênero e sexualidade. "A identidade masculina, branca, heterossexual deve ser, supostamente, uma identidade sólida, permanente, uma referência confiável" (LOURO, 2012, p. 44) a orientar condutas individuais e coletivas. As expressões que diferirem serão marginais. Ao identificar as expressões sexuais que escapam dos padrões heteronormativos, a heteronormatividade as mantém orbitando em torno de si. A produção discursiva da heteronormatividade produz, como efeitos, as expressões diversas que reforçam o lugar da heteronorma. O sujeito normativo da sexualidade é um efeito do discurso da 
heteronormatividade que se torna a referência sólida e as expressões sexuais destoantes serão discursivamente identificadas como anormais, serão os sujeitos do discurso sobre a anomalia.

Em 1975, Foucault (2001) ministrou onze aulas no Collège de France que foram reunidas em um livro intitulado "Os anormais". Foucault (2001) faz uma genealogia do conceito "anormal", identifica discursos sobre os anormais em três diferentes momentos históricos e mostra que esses discursos produziram três figuras distintas: no medievo o discurso sobre o anormal produziu o "monstro humano". "[...] o que define o monstro é o fato de que ele constitui, em sua existência mesma e em sua forma, não apenas uma violação das leis da sociedade, mas uma violação das leis da natureza" (FOUCAULT, 2001, p. 69). Entre os séculos XVII e XVIII o discurso sobre o anormal produziu o "indivíduo a ser corrigido" que na verdade é "[...] um incorrigível que vai ser posto no centro de uma aparelhagem de correção" (FOUCAULT, 2001, p. 73). Essa aparelhagem constitui-se de diferentes instituições que o confinarão e atuarão sobre ele, como a escola, hospitais e manicômios. Na passagem do século XVIII para o XIX, o discurso sobre o anormal produziu a "criança masturbadora". "O masturbador, a criança masturbadora, é uma figura totalmente nova no século XIX (é na verdade própria do fim do século XVIII), e cujo campo de aparecimento é a família" (FOUCAULT, 2001, p. 73). Apesar de haver, naquele tempo, a compreensão de que a prática da masturbação era frequente e universal, falar sobre isso era um tabu, por isso "A masturbação é o segredo universal, o segredo compartilhado por todo o mundo, mas que ninguém comunica a ninguém" (FOUCAULT, 2001, p. 73). Foucault (2001) mostra como o discurso sobre a anomalia produz o sujeito anormal em diferentes momentos históricos.

\footnotetext{
Esses três elementos começam a se isolar, a se definir, a partir do século XVIII e eles fazem a articulação com o século XIX, introduzindo esse domínio da anomalia que, pouco a pouco, vai recobri-los, confiscá-Ios, de certo modo colonizá-los, a ponto de absorvê-Ios. Esses três elementos são, no fundo, três figuras ou, se vocês quiserem, três círculos, dentro dos quais, pouco a pouco, o problema da anomalia vai se colocar (FOUCAULT, 2001, p. 69).
}

Atualmente, no que tange à sexualidade, os anormais são aqueles que diferem da heteronorma, a exemplo dos homossexuais. A lógica identitária é binária, assim sendo, toda norma tem seu correlato anormal. "[...] é um homem ou uma mulher, um rico ou um pobre, um adulto ou uma criança, um chefe ou um subalterno, "um x ou um y"” (DELEUZE; GUATTARI, 2012, p. 49). Em suma, no tocante à sexualidade, as diversas identidades sexuais decorrem da construção discursiva da heteronormatividade.

Diante disso, problematiza-se a noção de diversidade não para advogar seu fim, mas para questionar a lógica identitária dicotômica que a produz. Trata-se de questionar os estatutos identitários em vez de tomá-los como inquestionáveis e apenas reclamar seus lugares.

\section{Movimentos do currículo nos murais de uma escola}

Documentos oficiais que regem e/ou orientam a educação no Brasil reforçam a 
importância de uma educação pautada no respeito às diversidades. Esses documentos reverberam nos currículos e projetos políticos pedagógicos das escolas repercutindo nas práticas pedagógicas, conforme infere-se das fotografias abaixo. O critério de seleção dos murais fotografados foi a presença de práticas discursivas sobre diversidade. As fotografias foram feitas em novembro de 2017 em uma escola pública de Santa Catarina e foram utilizadas para compor as análises. A pesquisa foi autorizada pela instituição que tem seu nome preservado por questões éticas.

No dia 20 de novembro é celebrado no Brasil o dia nacional da consciência negra. A escola pesquisada celebrou, em 2017, não o dia, mas o mês da consciência negra. É importante ressaltar que as escolas fazem políticas e muitas não trabalham essas temáticas, outras sim, o que é importante em uma sociedade na qual os racismos ainda são muito presentes.

\section{Discurso de igualdade}

Figura 1. Mês da consciência negra

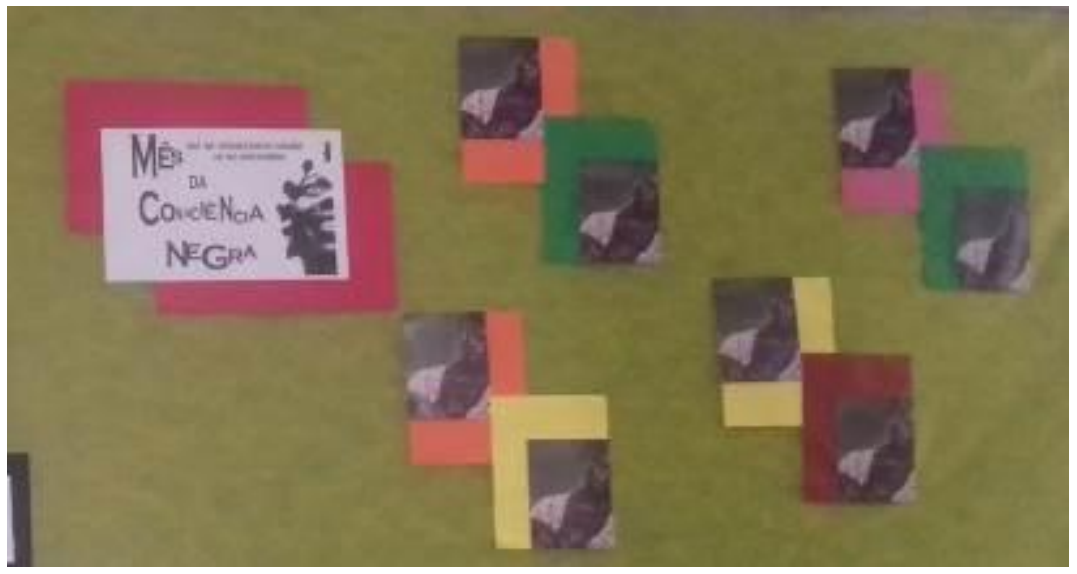

Fonte: Registro fotográfico realizado pelos autores.

Figura 2. Somos todos irmãos

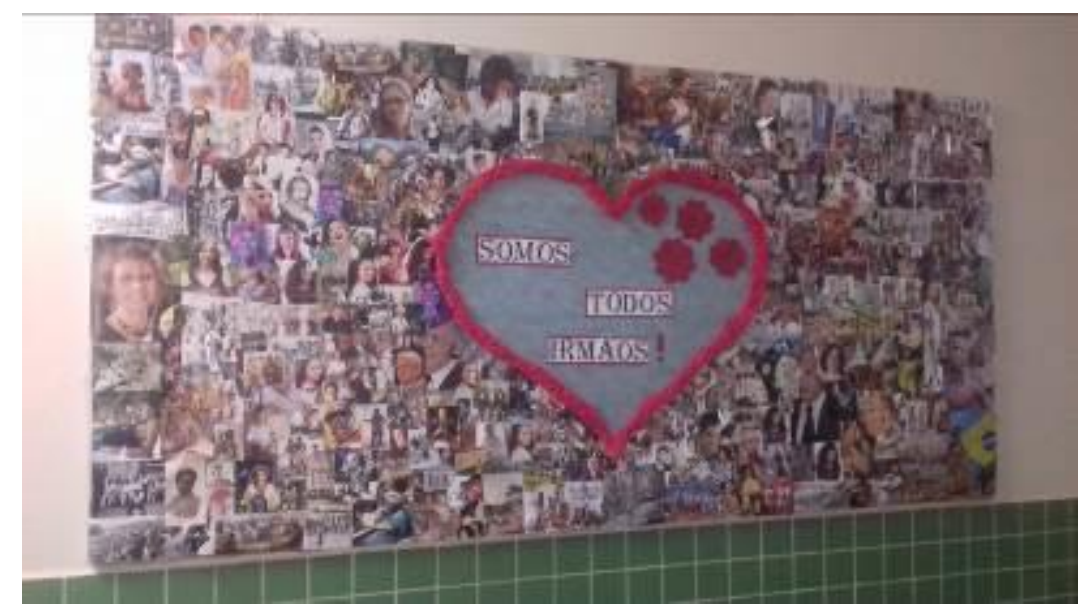

Fonte: Registro fotográfico realizado pelos autores. 
Figura 3. Consciência humana

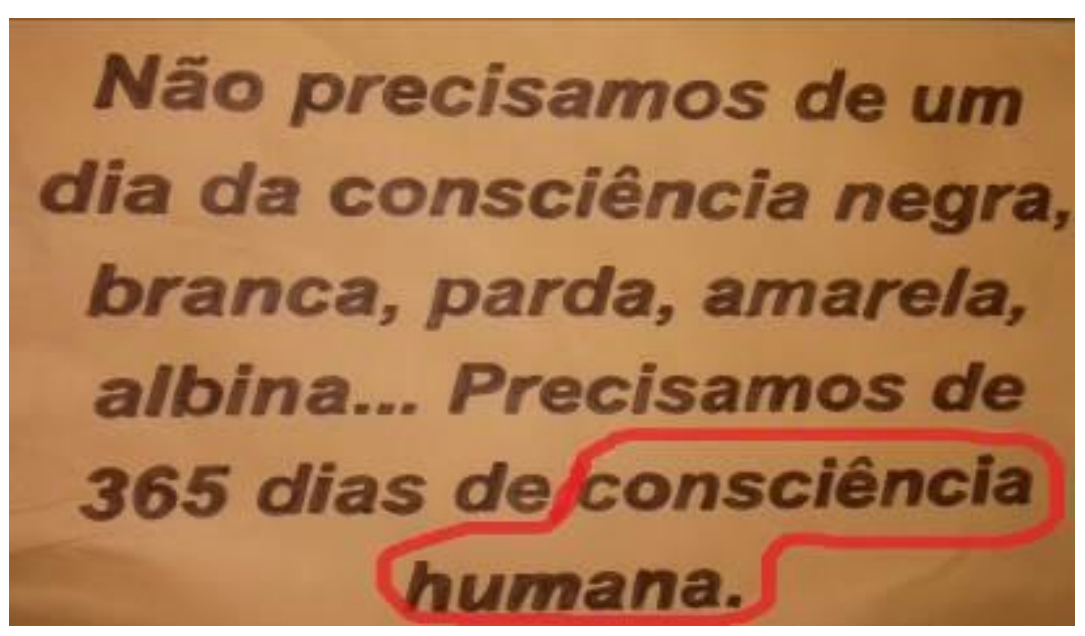

Fonte: Registro fotográfico realizado pelos autores.

Figura 4. Respeito às diferenças

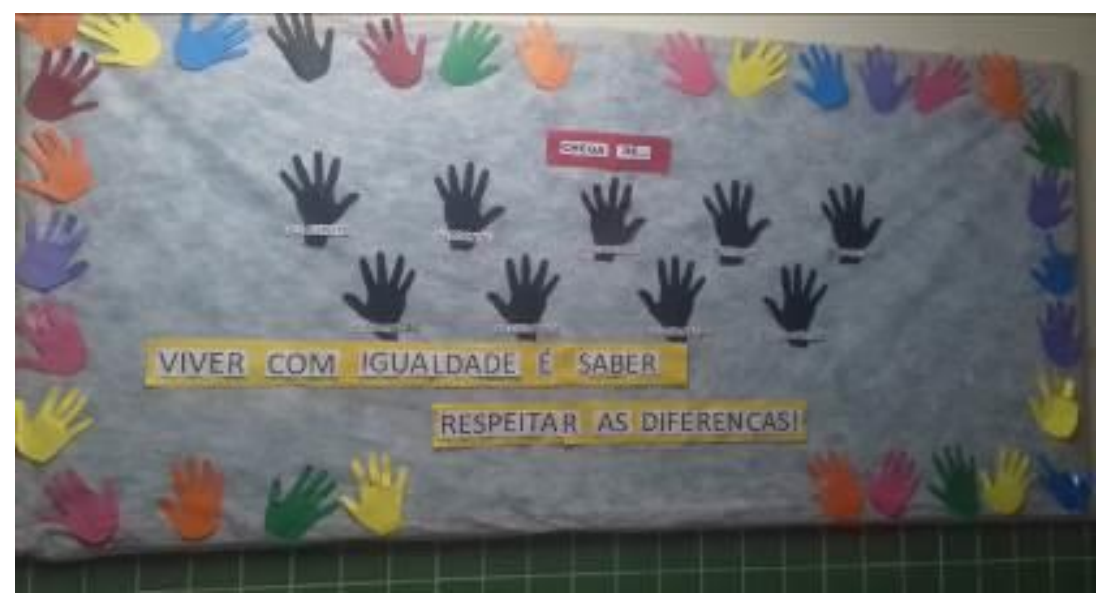

Fonte: Registro fotográfico realizado pelos autores.

Trabalhos realizados em disciplinas como história, sociologia e artes estavam expostos em murais distribuídos por toda a escola pesquisada. Sabe-se que as imagens utilizadas possibilitam múltiplas leituras, por isso, ressalta-se que optou-se por uma leitura dos discursos sobre diversidade presentes nas imagens. Essa leitura é feita pelas lentes da perspectiva da diferença visando problematizar os discursos de diversidade mapeados.

Um dos discursos encontrados nos murais foi o de igualdade. A partir dos trabalhos de estudantes, expostos nos painéis, foi possível perceber que a instituição promove discussões sobre a diversidade. "Viver com igualdade é saber respeitar as diferenças", diz o mural, mas o que é igualdade? A palavra igualdade é derivada do vocábulo igual que vem do grego "iso" e significa idêntico, portanto, sem diferença. Diante disso, pode-se apontar uma contradição na frase. Se igual é aquilo que é idêntico, viver com igualdade não é respeitar as diferenças, mas anulá-las em nome de uma unidade universal que inexiste. É tomar por idêntico aquilo que é multiplicidade, diferença. O discurso expresso no mural é o de que respeitar as diferenças, é deixar que o outro seja como eu sou, contudo, 
Respeitar a diferença não pode significar "deixar que o outro seja como eu sou" ou "deixar que o outro seja diferente de mim tal como eu sou diferente (do outro)", mas deixar que o outro seja como eu não sou, deixar que ele seja esse outro que não pode ser eu, que eu não posso ser, que não pode ser um (outro) eu; significa deixar que o outro seja diferente, deixar ser uma diferença que não seja, em absoluto, diferença entre duas identidades, mas diferença da identidade, deixar ser uma outridade que não é outra "relativamente a mim" ou "relativamente ao mesmo", mas que é absolutamente diferente, sem relação alguma com a identidade ou com a mesmidade (PARDO, 1996, p. 154).

Viver com igualdade, apregoa o mural, mas igualdade ao quê? A quem? A ideia de igualdade sempre pressupõe um referencial, pois se é igual é igual a alguma coisa. "O reconhecimento do 'outro', daquele ou daquela que não partilha dos atributos que possuímos, é feito a partir do lugar social que ocupamos" (LOURO, 1999, p. 15). A lógica que subjaz o discurso de igualdade presente no mural é identitária e [...] "a identidade é aquilo que faz passar a singularidade de diferentes maneiras de existir por um só e mesmo quadro de referência identificável" (GUATTARI; ROLNIK, 1996, p. 68-69), a identidade captura a diferença e não deixa espaço para o devir. As identidades sociais são moldes produzidos discursivamente que se sedimentam em alguma referência identificável. O discurso de igualdade pressupõe uma referência, uma identidade normatizadora e normalizadora, então, pensar em termos de igualdade é pensar em termos de representação, pois opera uma identificação e significação dos corpos.

É possível inferir que o termo diferença é empregado no mural como sinônimo de diversidade, mas "A diferença não é o diverso. O diverso é dado. Mas a diferença é aquilo pelo qual o dado é dado. É aquilo pelo qual o dado é dado como diverso" (DELEUZE, 1988, p. 209). A diferença é transgressão, variação, descentramento da norma.

Um dos murais foi confeccionado com imagens de pessoas de diferentes etnias, classes sociais, gêneros, gerações, etc. No centro do mural um grande coração abriga a frase: "somos todos irmãos". Novamente infere-se um discurso de igualdade. O mural com imagens de diferentes pessoas sobrepostas pela frase "somos todos irmãos" transmite a mensagem de que, apesar da diversidade, algo nos torna irmãos, uma característica universal. Trata-se da humanidade inerente a todos nós. Apesar da diversidade, somos todos humanos e isso nos torna iguais. A categoria humanidade é utilizada como fundamento para o discurso de igualdade, mas essa suposta igualdade é fantasiosa. O fato de sermos todos humanos não implica sermos todos iguais e pensar dessa forma pode fazer com que questões como relações de poder não sejam percebidas e discutidas. Ser igual é ser igual a. Diante disso, cabe perguntar: quem é esse "a"? Qual é a referência? A norma a partir da qual as identidades sociais são produzidas constitui-se pelo "[...] europeu médio adulto macho habitante das cidades [...]" (DELEUZE, 2013, p. 218). O discurso de igualdade faz as singularidades convergirem a esse referencial anulando a diferença à medida que produz, a partir do referente, identidades diversas. "[...] o indivíduo supõe a convergência de certo número de singularidades, determinando uma condição de fechamento sob a qual se define uma identidade" (ZOURABICHVILI, 2004, p. 54).

"Não precisamos de um dia da consciência negra, branca, parda, amarela, albina", pronuncia outro painel. Este enunciado toma a humanidade como uma categoria universal 
para advogar um discurso de igualdade que reduz a diferença a identidades e fomenta racismos. Trata-se de uma redução, pois "A identidade é da ordem da representação e da recognição: x representa y, x é y" (SILVA, 2002, p. 66), portanto, é sempre uma captura, uma tomada de poder pelo significante, conforme escrevem Deleuze e Guattari (2011). O discurso de igualdade marca aqueles que diferirem do referencial produzindo estratificação e exclusão. Em sua fábula, intitulada "A revolução dos bichos", George Orwell escreveu: "Todos os animais são iguais, mas alguns animais são mais iguais do que os outros" (ORWELL, 2002, p. 112). O discurso de igualdade toma diferentes como iguais, desconsidera as singularidades e produz essa hierarquização. Na perspectiva da igualdade, a célebre frase do escritor inglês poderia ser reescrita da seguinte forma: "Todos os humanos são iguais, mas alguns humanos são mais iguais do que os outros". Ou, ainda, alguns humanos são mais humanos que outros. Os discursos de igualdade mantêm intacta a estrutura normativa erigida a partir de uma lógica identitária, não a questionam. Dizer somos iguais é negar a diferença, pois a diferença não pode ser igual. Ela varia, ela devém.

\section{Discurso jurídico}

Uma das condições históricas que permitiu a irrupção de uma trama discursiva sobre igualdade, que fundamenta os discursos de respeito e tolerância à diversidade, foi a instauração do princípio da isonomia, previsto no artigo $5^{\circ}$ da Constituição Federal de 1988: “Art. $5^{\circ}$ Todos são iguais perante a lei, sem distinção de qualquer natureza, garantindo-se aos brasileiros e aos estrangeiros residentes no País a inviolabilidade do direito à vida, à liberdade, à igualdade, à segurança e à propriedade" (BRASIL, 1988). O princípio da isonomia passou a orientar a elaboração de leis e documentos oficiais da educação norteando a construção de currículos e colocando em circulação, via práticas pedagógicas, uma trama discursiva sedimentada nesse princípio.

Figura 2. Discurso jurídico

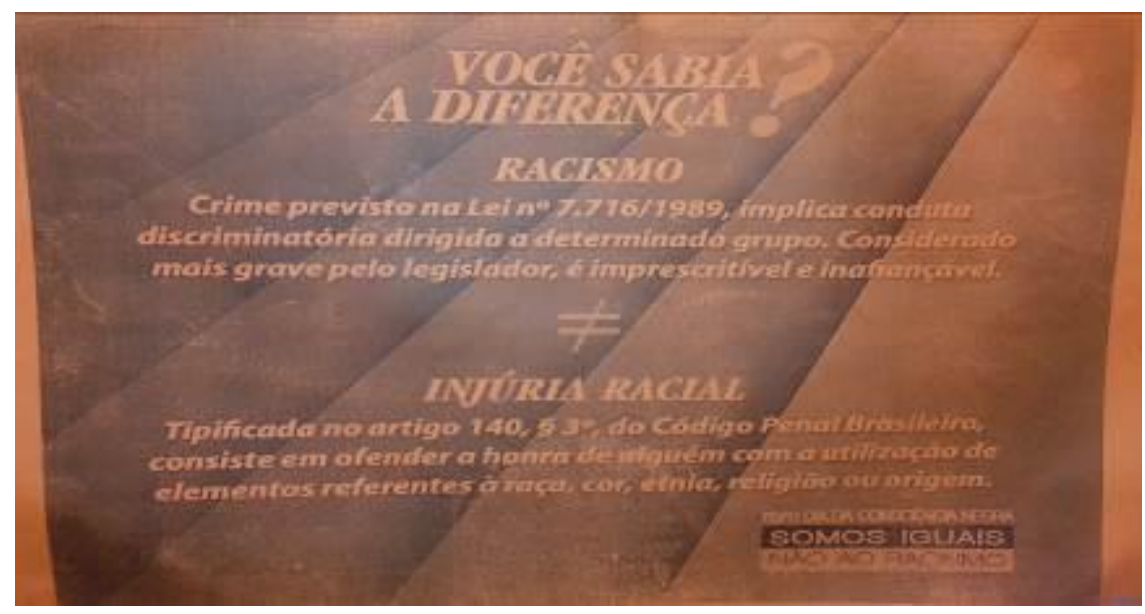

Fonte: Registro fotográfico realizado pelos autores.

Da imagem acima infere-se um discurso jurídico que produz um abrandamento das 
violências à medida que promove o silenciamento por medo da punição. No caso da Lei $\mathrm{n}^{\circ}$ 7.716 de 1989 que define os crimes resultantes de preconceito de raça ou de cor, a pena prevista para quem se recusar, negar ou impedir inscrição ou ingresso de estudantes em instituição de ensino, pública ou privada, por preconceito racial é de reclusão de três a cinco anos.

Art. $6^{\circ}$ Recusar, negar ou impedir a inscrição ou ingresso de aluno em estabelecimento de ensino público ou privado de qualquer grau. Pena: reclusão de três a cinco anos. Parágrafo único. Se o crime for praticado contra menor de dezoito anos a pena é agravada de 1/3 (um terço) (BRASIL, 1989).

Essa lei ampara-se na Constituição de 1988 que passou a considerar o racismo crime inafiançável e imprescritível. "XLII - a prática do racismo constitui crime inafiançável e imprescritível, sujeito à pena de reclusão, nos termos da lei” (BRASIL, 1988). A judicialização dos preconceitos é uma das condições de possibilidade de aparecimento de discursos sobre a diversidade no Brasil. Esses discursos passam a circular e reverberam em documentos educacionais e em currículos que passam a ser pautados em princípios como respeito, acolhimento, igualdade, participação, inclusão e tolerância à diversidade.

\section{Discurso de tolerância: eu tolero, tu toleras, nós toleramos...tolerar?}

Figura 3. Discurso de tolerância

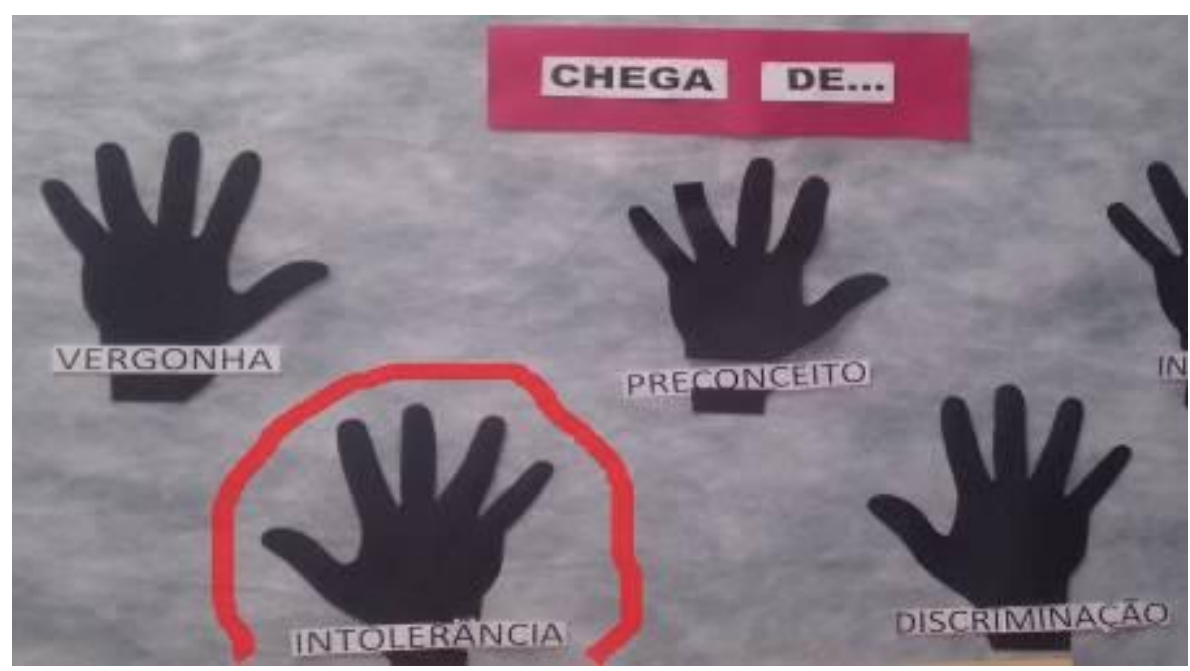

Fonte: Registro fotográfico realizado pelos autores.

De acordo com Lins (2005) a tolerância no sentido em que a tomamos atualmente surgiu no pensamento ocidental no século XVII, no Tratado Teológico de Espinosa publicado originalmente em 1670. Nesta obra, Espinosa propôs uma ética independente e tolerante como forma de rebelião contra a moral religiosa vigente na época. Lins (2005) escreve que é durante o século das luzes que o conceito de tolerância vai ser melhor desenvolvido e associado à ideia de democracia dará origem à Declaração dos Direitos Humanos e do Cidadão em 1789. O princípio iluminista de liberdade fez com que alguns pensadores começassem a desenvolver críticas à forte intolerância religiosa e, como resposta, surge a 
tolerância. "Os filósofos das Luzes, Voltaire em particular, ao pregar a tolerância, concluíam que o humano, dotado de razão, compreenderia a necessidade desse ideal e o aplicaria" (LINS, 2005, p. 24-25, grifo do original). "Chega de intolerância", anuncia o mural. O prefixo "in" sugere negação, destarte, trata-se de um pedido por tolerância.

$\mathrm{Na}$ escola pesquisada foi possível observar discursos jurídicos, de igualdade, e tolerância. Esses discursos transmitem a ideia de que discriminar é errado e que é preciso tolerar a diversidade, pois, se somos todos humanos somos todos iguais, logo, não há razão para a intolerância. Esse "iguais", contudo, tem um referente. Ao dizer somos iguais o que se está dizendo é que somos iguais à referência, mas "[...] a supremacia do sistema de referência não é posta em causa" (LINS, 2005, p. 26), a estrutura normativa não é questionada, não se leva em conta o fato de que ela é produção social do poder.

A diversidade é tomada como natural, mas ela é efeito do poder e é sempre composta por aqueles que são diferentes de nós. A diversidade são "os outros". Deste modo, a ideia de tolerância à diversidade deve ser problematizada, pois esse discurso parte sempre de uma norma a partir da qual os que destoam devem ser tolerados, mas " $\mathrm{O}$ simples fato de tolerar pressupõe uma certeza de possuir uma verdade... Esse modelo de tolerância, racismo de classe das oligarquias sociais, é de fato a intolerância legitimada pela violência simbólica" (LINS, 2005, p. 20). Ao tolerar, marca-se o outro como diverso. A tolerância é um discurso benevolente que parte sempre daqueles que se sentindo superiores se dispõem a tolerar os outros que são inferiores, pois distintos da norma. $\mathrm{O}$ normativo não precisa ser tolerado. Sobre ele não se fala. "É tolerando as exceções que se afirmam as regras, os pluralismos, as normas da obediência" (PASSETTI, 2004, p. 151). A norma não precisa ser tolerada é ela quem tolera. É sobre os diversos que se produzem discursos de tolerância que servem para reafirmar os lugares da norma e da anomia. A tolerância opera reforçando códigos identitários e realçando suas fronteiras delimitadas pela norma. Em suma, a tolerância camufla a perpetuação da estrutura normativa que permanece intacta. Sendo o currículo um

[...] espaço de significação [...] estreitamente vinculado ao processo de formação de identidades sociais. É aqui, entre outros locais, em meio a processos de representação, de inclusão e de exclusão, de relações de poder, enfim, que, em parte, se definem, se constroem, as identidades sociais que dividem o mundo social (SILVA, 1999, p. 27).

Desta forma, ao apregoar a tolerância pautando-se em uma lógica identitária o currículo adota um referente por meio do qual opera um processo de normalização. Normalizar pressupõe uma norma que ignora as singularidades dos indivíduos em nome de um universal. Assim, o currículo identifica, marca, classifica, reafirmando a norma e produzindo, como consequência, a diversidade. Esse processo de classificação, produz exclusão, pois “Todas as produções da cultura construídas fora deste lugar central assumem o caráter de diferentes e, quando não são simplesmente excluídas dos currículos, ocupam ali a posição do exótico, do alternativo, do acessório" (LOURO, 2012, p. 44-45). Ao fazer circular discursos jurídicos, de igualdade e tolerância à diversidade, o currículo reforça os lugares próprios à norma e à anomia reproduzindo e perpetuando relações assimétricas entre identidades normativas e os diversos. A diferença pura é anulada ao ser conformada em diversas identidades, haja vista que essas identidades são produzidas como o oposto da 
norma. Serão o anômico, o anormal.

\section{Considerações}

Observou-se que o discurso de igualdade atravessa os demais discursos mapeados parecendo conectá-los. A igualdade é o critério utilizado no discurso jurídico, cujas leis preveem penas a quem discriminar motivado por preconceitos de raça ou de cor. Discriminar significa distinguir, portanto, quando se atribui uma pena ao crime de racismo o que se está punindo é a inobservância do princípio constitucional de igualdade.

No que se refere ao discurso de tolerância, deve-se tolerar o outro que difere, pois, apesar de diferentes, o fato de sermos humanos nos faz iguais. A humanidade é o critério utilizado para apregoar a igualdade que é o fundamento dos discursos identificados nos trabalhos escolares expostos nos murais da escola e analisados. Entretanto, a igualdade é produção social do poder, pois emana de uma identidade normativa que opera um processo de hierarquização que coloca alguns no lugar central e outros às margens. A diferença é capturada e confinada em identidades sob o discurso de acolhimento da diversidade que mascara relações de poder.

As análises de trabalhos escolares expostos nos murais da escola revelaram movimentos de um currículo pautado na diversidade que é um efeito dos discursos e surge a partir da instauração de uma norma. O currículo, ao adotar essa norma, reproduz o processo de produção dos sujeitos normativos e diversos mantendo intacta a lógica binária que produzirá efeitos sobre os corpos identificados enquanto camufla as operações do poder sob o discurso de acolhimento da diversidade.

Os discursos jurídicos, de igualdade e de tolerância estão presentes em documentos oficiais da educação e repercutem nas escolas via currículo e práticas pedagógicas, conforme se vê nas imagens utilizadas neste trabalho. A circulação desses discursos produz estatutos de verdade que criam um consenso tolerante aos diversos, mas não questiona a estrutura normativa que os produziu.

Um currículo pensado na perspectiva da diferença deleuzeana se movimenta com as diferenças em vez de identificá-las. Não as descreve transformando-as em identidades, mas segue os fluxos de devires, reinventando-se a todo momento, escapando e fazendo fugir. Este currículo é multiplicidade e recusa a existência de um referente a partir do qual as identidades marginais são forjadas.

O que pode o currículo? Pode ser máquina de guerra e permitir o fluxo das diferenças a fim de romper os claustros identitários nos quais encarcera-se sua potência. Pensar em termos de diferença em vez de diversidade pode desestabilizar a organização hierárquica hegemônica da lógica binária identitária e isso permite pensar com a escola outros modos de fazer escolas. 


\section{Referências}

BRASIL. Base Nacional Comum Curricular (versão final). 2017. Disponível em: http://basenacionalcomum.mec.gov.br/wp-content/uploads/2018/02/bncc-20dez-site.pdf. Acesso em: 20 mar. 2018.

BRASIL. Constituição Federal de 1988. Promulgada em 5 de outubro de 1988. Diário Oficial [da] União, Poder Executivo, Brasília, DF, 5 out. 1988.

BRASIL. Diretrizes Curriculares Nacionais Gerais da Educação Básica. Ministério da Educação. Secretária de Educação Básica. Diretoria de Currículos e Educação Integral. Brasília: MEC, SEB, DICEI, 2013.

BRASIL. Lei no 9.394 de 20 de dezembro de 1996. Estabelece as Diretrizes e Bases da Educação Nacional. Diário Oficial [da] União, Poder Executivo, Brasília, DF, 23 dez. 1996.

BRASIL. Lei $\mathrm{n}^{\circ}$ 7.716, de 5 de janeiro de 1989. Define os crimes resultantes de preconceito de raça ou de cor. Diário Oficial [da] República Federativa do Brasil, Poder Executivo. Brasília, DF: Senado Federal, 1989.

BRASIL. Parâmetros curriculares nacionais: terceiro e quarto ciclos do ensino fundamental: introdução aos parâmetros curriculares nacionais. Brasília: MEC/SEF, 1998. Disponível em: http://portal.mec.gov.br/seb/arquivos/pdf/introducao.pdf. Acesso em: 21 mar. 2018.

BUTLER, Judith. Corpos que pesam: sobre os limites discursivos do "sexo". In: LOURO, Guacira Lopes (Org.). O corpo educado: Pedagogias da sexualidade. Belo Horizonte: Autêntica, 1999. p. 151-172.

CASTRO, Edgardo. Vocabulário de Foucault: um percurso pelos seus temas, percursos e autores. Tradução Ingrid Müller Xavier. 2. ed. Belo Horizonte: Autêntica, 2016.

DELEUZE, Gilles. Conversações, 1972-1990. Tradução de Peter Pál Pelbart. São Paulo: Editora 34, 2013.

DELEUZE, Gilles. Diferença e repetição. Tradução Luiz Orlandi e Roberto Machado. Rio de Janeiro: Graal, 1988.

DELEUZE, Gilles; GUATTARI, Félix. Mil platôs: capitalismo e esquizofrenia. 2 ed. Tradução Ana Lúcia de Oliveira, Aurélio Guerra Neto e Célia Pinto Costa. Rio de Janeiro: Editora 34, 2011. v. 1.

DELEUZE, Gilles; GUATTARI, Félix. Mil platôs: capitalismo e esquizofrenia. Tradução Aurélio Guerra Neto, Ana Lúcia de Oliveira, Lúcia Cláudia Leão e Suely Rolnik. Rio de Janeiro: Editora 34, 2012. v. 3.

FOUCAULT, Michel. A arqueologia do saber. 7. ed. Tradução Luiz Felipe Baeta Neves. Rio de Janeiro: Forense Universitária, 2008. 
FOUCAULT, Michel. Vigiar e punir: nascimento da prisão. 20 ed. Tradução Raquel Ramalhete. Petrópolis: Vozes, 2007.

FOUCAULT, Michel. Os anormais: Curso no Collège de France (1974-1975). Tradução Eduardo Brandão. São Paulo: Martins Fontes, 2001.

GOLDENBERG, Mirian. A arte de pesquisar: como fazer pesquisa qualitativa em ciências sociais. 8. ed. Rio de Janeiro: Record, 2004.

GUATTARI, Félix; ROLNIK, Suely. Micropolítica: cartografias do desejo. 4. ed. Petrópolis: Vozes, 1996.

HALL, Stuart. Quem precisa da identidade? In: SILVA, Tomaz Tadeu da (Org.); HALL, Stuart; WOODWARD, Kathryn. Identidade e diferença: a perspectiva dos estudos culturais. Petrópolis: Vozes, 2012. p. 103-133.

LINS, Daniel. Tolerância ou imagem do pensamento?. In: PASSETI, Edson; OLIVEIRA, Salete de (Org.). A tolerância e o intempestivo. Cotia, SP: Ateliê Editorial, 2005. p. 19-33.

LOURO, Guacira Lopes. Currículo, gênero e sexualidade - O "normal”, o "diferente" e o "excêntrico". In: LOURO, Guacira Lopes; FELIPE, Jane; GOELLNER, Silvana Vilodre (Org.). Corpo, gênero e sexualidade: um debate contemporâneo na educação. 8 ed. Petrópolis: Vozes, 2012. p. 43-53.

LOURO, Guacira Lopes. O corpo educado: pedagogias da sexualidade. Belo Horizonte: Autêntica, 1999. 174p.

ORWELL, George. A revolução dos bichos. Tradução Heitor Aquino Ferreira. São Paulo: Globo, 2002.

PARDO, José Luis. El sujeto inevitable. In: CRUZ, Manuel (Org.). Tiempo de subjetividad. Tradução Tomaz Tadeu da Silva. Barcelona: Paidós, 1996. p. 133-154.

PASSETTI, Edson. Segurança, confiança e tolerância: comandos na sociedade de controle. São Paulo em Perspectiva, v. 18, n. 1, p. 151-160, jun. 2004.

SILVA, Tomaz Tadeu da. Identidade e diferença: impertinências. Educação e sociedade. São Paulo, ano 23, n. 79, p. 65-66, ago. 2002.

SILVA, Tomaz Tadeu da. O currículo como fetiche: a poética e a política do texto curricular. Belo Horizonte: Autêntica, 1999.

SCHWENGBER, Maria Simone Vione. O uso das imagens como recurso metodológico. In: MEYER, Dagmar Estermann; PARAÍSO, Marlucy Alves (Org.). Metodologias de pesquisas pós-críticas em educação. 2. ed. Belo Horizonte: Mazza Edições, 2014. p. 263-280.

ZOURABICHVILI, François. O vocabulário de Deleuze. Rio de Janeiro: Sinergia - Relume Dumará, 2004.

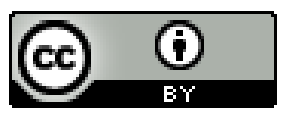

